\title{
Gustavo Ernesto Emmerich
}

Profesor de ciencia política en la Universidad Autónoma Metropolitana, unidad Iztapalapa, e investigador del Sistema Nacional de Investigadores, nivel II. Uno de sus temas de investigación son las relaciones entre México y Estados Unidos de América, tanto en la actualidad como históricas.

\section{Resumen}

En 1836 el ejército mexicano tomó el fuerte de El Álamo, en las afueras de San Antonio. Todos sus defensores, que combatían por la independencia de Texas, murieron en la acción, entre ellos Gregorio Esparza, un nativo de esa ciudad. Tras la batalla, su hermano Francisco, enrolado en el bando mexicano, le dio cristiana sepultura. Este artículo examina la saga de ambos hermanos virtualmente desconocida en México. La primera sección de este artículo contextualiza la independencia de Texas, la segunda contiene resultados de investigación documental realizada por el autor sobre Gregorio y
Francisco Esparza. La tercera comenta una entrevista realizada a un hijo de Gregorio sobre los papeles de su padre y su tío en El Álamo. La cuarta evalúa críticamente las evidencias. La quinta ofrece una reflexión sobre los motivos que habrían llevado a los hermanos Esparza -y en general a la comunidad texana de origen mexicano- a enfrentarse respecto a la independencia de Texas y, finalmente, en los anexos se transcriben los registros parroquiales y censales de la época y se extractan y comentan diversos relatos del hijo de Gregorio y de otros descendientes.

Palabras clave:

Gregorio Esparza, Francisco Esparza, Texas, Tejas, El Álamo, batalla de El Álamo, independencia de Texas, mexicanos en Texas.

Fecha de recepción: octubre de 2010
Fecha de aceptación:

junio de 2011 


\title{
Gregorio and Francisco Esparza: Brothers Who Fought Each Other During the Independence of Texas, 1835-1836
}

\author{
Gustavo Ernesto Emmerich
}

Political science professor at the Universidad Autónoma Metropolitana, Iztapalapa Campus, and Level II National Researcher in the National Researchers' System. One of his research topics are the current and historical relations between Mexico and the United States.

\begin{abstract}
In 1836, the Mexican army captured Fort Alamo outside San Antonio. All its defenders, who were fighting for the independence of Texas, died in action. Among these was Gregorio Esparza, a native of that city. After this battle, his brother Francisco, enlisted in the Mexican army, gave him a Christian burial. This article examines the saga of the two brothers, virtually unknown in Mexico. The first section contextualizes the independence of Texas. The second contains the results of the author's documentary research on Gregorio and Fran-

cisco Esparza. The third comments on an interview with one of Gregorio's sons on the roles played by his father and uncle at The Alamo. The fourth critically evaluates the evidence. The fifth provides a reflection on the reasons that led the Esparza brothers -and the Texan community of Mexican origin - to fight each other over the independence of Texas. The last section contains appendices with transcriptions of the parish records and censuses of the time and comments on the accounts of Gregorio's son and other descendants.
\end{abstract}

Key words:

Gregorio Esparza, Francisco Esparza, Texas, Tejas, The Alamo, Battle of The Alamo, Independence of Texas, Mexicans in Texas.

Final submission: Acceptance:

October 2010 June 2011 


\title{
Gregorio y Francisco Esparza: hermanos enfrentados ante la independencia de Texas, 1835-1836
}

\author{
Gustavo Ernesto Emmerich*
}

\section{INTRODUCCIÓN}

$\mathrm{E}$ 16 de marzo de 1836 las tropas mexicanas tomaron por asalto el fuerte de El Álamo, situado en el actual San Antonio. Todos sus defensores, partidarios de la independencia de Texas, cayeron en la acción; ${ }^{1}$ entre ellos, Gregorio Esparza, un nativo de esa ciudad. Finalizada la batalla, fue sepultado por su hermano Francisco, enrolado en el bando mexi-

\footnotetext{
* El apoyo de la Secretaría de Relaciones Exteriores de México, a través de su Programa de Estancias Cortas de Investigación Bibliográfica en la Colección Latinoamericana Nettie L. Benson de la Universidad de Texas, en Austin, fue fundamental para esta investigación. Asimismo, agradezco el amplio acceso que me otorgaron a los respectivos archivos: Warren Stricker, de "The Daughters of the Republic ot Texas Library" (DRTL); Hermano Edward Loch, de los Catholic Archives at San Antonio; Alfred Rodriguez, de la Bexar County Courthouse (BCC); Robert Cornejo, de los Catholic Cemeteries at San Antonio; todos ellos de San Antonio, y a Galen D. Greaser, de la Texas General Land Office (GLO), de Austin.

${ }^{1}$ El número de defensores muertos es incierto: hasta la década de 1980 se aceptaba que eran 182; posteriores investigaciones agregaron siete más. De todos estos, siete eran de origen mexicano (Matovina, Alamo, 1998, pp. 3 y 32), los restantes de origen estadunidense o europeos asimilados.
}

cano. La saga de dos hermanos enfrentados en bandos opuestos tiene indudable calor humano, y ha sido muy socorrida en la historiografía texana. En cambio, en México poco o nada se conoce de ellos, lo que amerita dar a conocer su historia. En particular, porque pone de manifiesto la desgarradora división que sufrió la comunidad de raíz mexicana allí residente, frente al movimiento que llevó a Texas a independizarse de la república mexicana.

El papel de los hermanos Esparza en la independencia texana adquirió luz pública a principios del siglo XX, por vía de los relatos de un hijo de Gregorio publicados en periódicos de San Antonio. Gregorio se había incorporado en octubre de 1835 a un grupo independentista de origen mexicano, y participado en diciembre de 1835 en la toma de San Antonio por los rebeldes. En febrero de 1836, las tropas mexicanas reconquistaron la ciudad y pusieron sitio a El Álamo. Gregorio, con esposa e hijos, se refugió en el fuerte, donde murió combatiendo el 6 de marzo. Por su lado, su medio hermano Francisco Esparza se había enrolado desde tiempo atrás en la Leal Compañía Presidial de San Antonio, la guarnición local mexicana. En diciembre de 1835 , esta compañía capituló ante los rebeldes, y ya no volvió a ser 
movilizada por los mexicanos. Aunque no luchó en El Álamo, Francisco pidió permiso a sus superiores para buscar el cuerpo de Gregorio y darle cristiana sepultura. Lo salvó así de la pira funeraria en que fueron incinerados los restos de los demás vencidos. Investigaciones ulteriores confirmaron en lo sustancial estos datos, al revelar que a mediados del siglo XIX el estado de Texas había otorgado tierras a los herederos de Gregorio Esparza, en compensación por los servicios prestados por el difunto a la causa independentista; y también al propio Francisco, en este caso por el solo hecho de haber residido en Texas al momento de su independencia.

Gregorio Esparza es oficialmente un héroe de la independencia de Texas. Su apellido figura en sendos monumentos a los caídos erigidos frente a El Álamo y en los jardines del Congreso texano, en Austin. En el museo de El Álamo abundan las menciones a su heroísmo, y en la iglesia del lugar -hoy convertida en santuario- ocupa un lugar destacado en una pintura de Cecil Casebier (1950): representa a Gregorio y al jefe de los independentistas -el coronel William B. Travisamunicionando un cañón sobre el techo de la propia iglesia, al momento de ser ultimados por tropas mexicanas. La bibliografía que menciona a Gregorio Esparza es abundante, ya sea considerado en conjunto con los otros defensores de El Álamo, o dedicada específicamente a él; ${ }^{2}$ en San Antonio hay incluso una escuela que lleva su nombre. En cambio, Francisco Esparza aparece siempre en un papel secundario: sepultó a su hermano menor, se encargó de

\footnotetext{
${ }^{2}$ Véanse, por ejemplo, Laos, Esparza, 1999; Matthews, Gregorio, 1996; Ragsdale, Women, 1994, y otra bibliografía que se agregará en notas a pie de página.
}

la familia del difunto, y se quedó a vivir en Texas. Su experiencia es epítome de la de muchos que durante el conflicto habían apoyado la unidad con México: permanecieron en Texas, renovaron sus lazos familiares, amicales y laborales, y algunos consiguieron incluso prosperar en una república que rápidamente se les hizo ajena.

Este artículo examina la saga de Gregorio y Francisco Esparza con base en registros, documentos, testimonios y relatos. Su primera sección reseña aspectos generales de la independencia de Texas. La segunda contiene los resultados de la investigación documental que yo realicé sobre Gregorio y Francisco Esparza. La tercera comenta la primera entrevista -realizada en 1901-al hijo de Gregorio, sobre los papeles de su padre y su tío en El Álamo. La cuarta evalúa críticamente las evidencias. La quinta ofrece una reflexión sobre los motivos que habrían llevado a los hermanos Esparza -y en general a la comunidad texana de raigambre mexicana-a dividirse y enfrentarse respecto de la independencia de Texas, y finalmente, en los anexos se transcriben los registros parroquiales y censales de la época, y se extractan y comentan otros relatos del hijo de Gregorio y de otros descendientes.

\section{LA INDEPENDENCIA DE TeXas}

Al consumarse su independencia en 1821 , México heredó en términos generales el territorio del virreinato de Nueva España, incluyendo lo que hoy es el estado (estadunidense) de Texas. Tejas, como se escribía en español en esa época, tenía sólo unos 2500 habitantes de origen español o mexicano, y una cantidad indetermi- 
nada de indígenas nómadas y belicosos. $\mathrm{Al}$ ver que su corta población era inferior a la necesaria para constituir un estado, al establecerse la república mexicana en 1824 quedó como parte del estado de Coahuila y Tejas.

Los gobiernos mexicanos ${ }^{3}$ fomentaron la inmigración hacia Texas a través de "empresarios", a los que otorgaban concesiones de tierras a cambio de que estos introdujesen colonos europeos o estadunidenses. En 1836 Texas había crecido a 39000 habitantes, de los cuales 30000 eran estadunidenses o europeos asimilados a la cultura estadunidense, 4000 eran de origen hispano o mexicano, y otros 5000 eran negros, ya sea libertos o esclavos (estos últimos introducidos contra las leyes mexicanas que prohibían la esclavitud); estas cifras no consideran a la población indígena. ${ }^{4}$

En esos tiempos, era habitual denominar tejanos a los habitantes de origen hispano o mexicano, y anglos a los inmigrantes estadunidenses y europeos asimilados; en este artículo, la expresión texanos se utilizará cuando se haga referencia a ambos grupos en conjunto. Los tejanos se asentaban principalmente en San Antonio (que hasta 1837 se llamó San Fernando de Béxar, y era más conocido como simplemente Béxar) y en el sur. Los anglos predominaban en el este, cercano a Luisiana y las riberas del Golfo de México. El oeste y el norte estaban todavía en manos indígenas. Los mayores centros poblacionales eran San Antonio, sede de las autoridades mexicanas, junto con Goliad y Nacog-

\footnotetext{
${ }^{3}$ La corona española había otorgado ya concesiones a empresarios, mismos que los primeros gobiernos mexicanos independientes refrendaron y ampliaron.

${ }^{4}$ Daughters, Alamo, 1985, p. 13.
}

doches, principales focos de inmigración de los anglos. Estas y otras poblaciones menores gustaban de regirse con gran autonomía a través de ayuntamientos electos por sus habitantes.

Los texanos se sentían desatendidos por las autoridades mexicanas. La legislatura de Coahuila y Texas comprendía diez diputados de la primera, contra sólo uno -y luego dos- de la segunda. Las distancias hasta la capital estatal -Saltillo, en el actual estado mexicano de Coahuila- o a la ciudad de México eran difíciles de cubrir. Los vínculos hacia el resto de México se dificultaban, y el comercio se orientaba geográficamente hacia el puerto estadunidense de Nueva Orleans. Los constantes pronunciamientos y cambios de gobierno en México eran mal vistos en una Texas aislada, cuyos habitantes se caracterizaban por un fuerte individualismo y su afán de poseer tierras. El ejército mexicano, casi siempre involucrado en guerras civiles, no los protegía efectivamente de los ataques de indígenas hostiles. Decididos partidarios del federalismo, muchos texanos habrían preferido que Texas fuese un estado mexicano por sí mismo y separado de Coahuila, o bien, una república independiente, o incluso un estado más de los Estados Unidos de América (EUA).

Tras años de tensiones y enfrentamientos esporádicos con los gobiernos mexicanos, los anglos y algunos tejanos se levantaron en armas en el otoño de 1835. Meses antes, el presidente Antonio López de Santa Anna había desconocido la Constitución federalista y liberal de 1824, implantando un estricto centralismo y asumiendo poderes dictatoriales. Esto generó descontento y revueltas en varios lugares, incluida Texas. El 2 de octubre de 1835 tropas mexicanas y colonos texanos se enfrentaron en 
González, unos kilómetros al este de San Antonio, lo que marcó el inicio de las hostilidades. Una convención reunida en San Felipe (la actual Austin) emitió la "Declaración de Causas" (3 de noviembre) en la que decía querer mantenerse dentro de los Estados Unidos Mexicanos, pero con arreglo a la Constitución de 1824, a la que siguió la "Declaración del pueblo de Tejas" (7 de noviembre) que manifestaba que este "ha tomado las armas en defensa de sus derechos y libertades amenazados por los ataques del despotismo militar; y en defensa de los principios de la Constitución federal de Mejico [sic], sancionada en 1824". 5 La Convención estableció un gobierno provisional y promovió la llegada de voluntarios desde Estados Unidos, ofreciendo tierras en compensación por su participación en el levantamiento.

En diciembre de 1835, los rebeldes tomaron San Antonio, y con ella El Álamo. Con este nombre era conocida la antigua misión de San Antonio de Valero, que desde 1793 había dejado de prestar servicios religiosos para convertirse en un fuerte o "presidio", según la terminología española de la época. Los vencedores ofrecieron una capitulación honorable al general José María Perfecto de Cos, comandante de la guarnición mexicana y cuñado de Santa Anna. Cos y sus soldados juraron no volver a tomar las armas contra Texas o contra la Constitución de 1824, y la mayoría se retiró al sur del río Bravo o Grande del Norte; a los pocos residentes

\footnotetext{
${ }^{5}$ Véase reproducción facsimilar de la Declaración en Daughters, Álamo, 1985, p.18. Según Henson, (Lorenzo, 1996, p. 94), la declaración fue traducuda al español por el líder liberal mexicano que da título a su libro y que desempeñó un papel destacado en la independencia de Texas.
}

en Texas, como Francisco Esparza, se les permitió permanecer en sus domicilios.

Santa Anna desconoció la capitulación y se aprestó a recuperar Texas. Sin hallar resistencia, reocupó San Antonio el 23 de febrero de 1836. Los rebeldes locales se refugiaron en El Álamo, que Santa Anna sitió. El 6 de marzo, antes de clarear el día, sus tropas capturaron el fuerte, aniquilando a sus defensores; no está claro si todos cayeron en combate o si algunos pocos fueron ejecutados tras su rendición. ${ }^{6}$

Mientras tanto, el 2 de marzo, en Washington-on-the-Brazos, los texanos habían declarado la independencia de la República de Texas. El 21 de abril, en San Jacinto (a mitad de camino entre las actuales Houston y Galveston), aplastaron una tropa de unos 1500 mexicanos comandados por Santa Anna. Capturado y al parecer bajo amenaza de muerte, el 14 de mayo Santa Anna firmó los "tratados de Velasco" con el presidente interino de la República de Texas, David G. Burnet. Uno de ellos, público, disponía que Santa Anna cesaría inmediatamente todas las hostilidades, retiraría su ejército al sur del río Bravo, y no volvería a tomar las armas contra Texas. El otro, secreto, establecía que Santa Anna procuraría el reconocimiento de la independencia de la República de Texas, y definía al río Bravo como el límite entre México y la nueva República. Meses después, Santa Anna fue liberado y volvió a México.

Fue así como Texas se independizó en 1836. El 19 de febrero de 1846 se anexó a Estados Unidos. La independencia de Texas fue reconocida por México apenas en 1848, como parte del Tratado de

\footnotetext{
${ }^{6}$ Para un recuento de la batalla, véanse Myers, Alamo, 1973, y Tinkle, Days, 1958.
} 
Guadalupe Hidalgo que puso fin a la guerra con Estados Unidos estallada en 1846, precisamente por un incidente en la frontera texano-mexicana. ${ }^{7}$

Tanto en México como en Estados Unidos, la guerra de independencia de Texas fue durante mucho tiempo concebida como una lucha entre anglos que ansiaban anexionarse a Estados Unidos, y tejanos que querían seguir siendo parte de México. Entre los motivos de esta lucha habría estado el deseo de los anglos de implantar en el territorio texano la esclavitud, prohibida por las leyes mexicanas. El desemboque final de los acontecimientos convalida en parte esta interpretación. La esclavitud se implantó, Texas se anexó a Estados Unidos, y poco después de la independencia los tejanos y sus descendientes comenzaron a ser relegados y marginados por los anglos. ${ }^{8}$

No obstante, bastantes tejanos se unieron a la rebelión, como se muestra en este artículo. Su meta habría sido no la anexión a Estados Unidos, sino restablecer la Constitución federalista mexicana de 1824; ante la imposibilidad de lograrlo, aceptaron como mal menor constituir una república independiente y ajena a las permanentes turbulencias políticas de México. Ingenuos se vieron: la nueva república, en la que eran minoría y separada de México, fue fundada bajo predominio anglo, e iba a gravitar naturalmente hacia

${ }^{7}$ Por este mismo tratado, México renunció a sus territorios más norteños, que hoy forman los estados (estadunidenses) de California, Nevada, Colorado, Nuevo México y Arizona.

${ }^{8}$ Montejano (Anglos, 1991, especialmente pp. 36-55) describe un proceso de exclusión social e incluso expulsión física de los tejanos que siguió a la independencia y continuó con los años. la esfera de influencia estadunidense. Ello no impidió, sin embargo, que la comunidad tejana se acomodase a la nueva situación, aunque de forma cada vez más subordinada.

\section{INVESTIGACIÓN DOCUMENTAL}

Parentesco, nacimiento y vida de los hermanos Esparza

En los registros de la iglesia de San Fernando, en San Antonio, se encuentra la inscripción del matrimonio celebrado en 1799 entre Juan Antonio Esparza, mestizo, y María Petra Olivas, "española" (por "blanca", en la terminología de la colonia). Esta pareja engendró varios hijos, ${ }^{9}$ entre ellos, en 1804, a José Francisco Nepomuceno (Francisco Esparza).

El 8 de marzo de 1808, María Petra Olivas dio a luz a José Gregorio (o simplemente Gregorio Esparza). ${ }^{10}$ Según su

\footnotetext{
${ }^{9}$ María Josefa Ermenegilda (1800), Juan Nepomuceno (1801), los gemelos Antonio Tomás Cesario y José María Cesario (1802), José Francisco Nepomuceno (1804) y Víctor Filomeno (1806), algunos de los cuales murieron en la infancia; véase Daughters of the Republic of Texas Library (en adelante DRTL), "Historic Sites - Alamo Defenders - Gregorio Esparza - Genealogy".

${ }^{10}$ Esta fecha coincide con la genealogía elaborada por Walter Laos en ibid., uno de los descendientes de Gregorio Esparza, y con la fecha de nacimiento aceptada por la escuela de San Antonio que lleva su nombre, que anualmente celebra la Semana de Gregorio Esparza en el aniversario de su venida al mundo. Diversos investigadores proporcionan fechas diferentes, e incluso genealogías y nombres que en realidad corresponden a otros Esparza que vivieron en San Antonio en las primeras décadas del siglo XIX. Por ejemplo de Williams, "Critical", 1934, parte v, p. 257,
} 
registro de bautismo, el padre era "desconocido" (Juan Antonio Esparza había fallecido hacia $1806^{11}$ ). Al margen del registro figura la inscripción "h. l." (por "hijo legítimo"), mientras que el texto principal dice "hijo natural". El recién nacido es caracterizado como "párbulo [sic] español". Dado que su madre era "española", y considerando el rígido sistema de castas existente en la colonia, puede inferirse que el padre de Gregorio fue blanco y de origen español, y que su vástago no reconocido adquiría luego el apellido del difunto esposo de su madre. En cambio, Francisco, su medio hermano mayor, había sido bautizado como "mestizo", al igual que su padre Juan Antonio Esparza.

Censos levantados por autoridades primero españolas y después mexicanas, asî como registros parroquiales, aunque con errores en cuanto a edades, apellidos y nombres, confirman que Gregorio y Francisco Esparza crecieron y formaron familias en San Antonio. Según tales censos, en 1803 Juan Esparza vivía con Marta Petra Olivas y su primera hija en común (María Josefa Ermenegilda). En años posteriores, es Petra quien aparece como jefa de una pequeña familia integrada por ella y sus hijos Francisco y Gregorio (a la cual retorna luego su hija mayor). En 1828 Francisco se casa, y se revela que es sol-

se desprende que Gregorio Esparza habría nacido en 1803; según Handbook, 1996, José María (Gregorio) Esparza habría nacido el 25 de febrero de 1802; según Groneman (Alamo, 1990, p. 45), José Gregorio Esparza habría nacido el 3 de agosto de 1808; según Miller ("Mexican”, 1971, p. 34), Gregorio Esparza habría nacido en 1803, "hijo de José Ignacio y Nicolasa Ramírez Esparza".

${ }^{11}$ Véase Laos, en DRTL, "Historic Sites - Alamo Defenders - Gregorio Esparza - Genealogy”. dado en la guarnición local. En 1829, Gregorio figura como jornalero, casado con Ana Salazar, quien tenía una hija de un matrimonio anterior, y con quien engendraría a Enrique y Manuel Úrsulo. Los registros pertinentes se transcriben y comentan en el anexo 1, que muestra la evolución de la familia Esparza de 1799 hasta 1831.

En 1835, en pleno torbellino revolucionario, el testamento de José María Zambrano, del 23 de diciembre, revela que Gregorio Esparza se ocupaba en empleos humildes y estaba endeudado: ${ }^{12}$

12. Ytem declaro: que todas las deudas que aparecen en mi favor las perdono y es mi boluntad no cobrarles a los individuos que me deven y sólo quiero que a mi sirviente Gregorio Esparza se le cobren diez pesos que ha ofrecido darme por toda la deuda, cuyos diez pesos dejo a veneficio de mi comadre Sabia. ${ }^{13}$

\section{Sepultura de Gregorio Esparza}

Como se verá más adelante, Francisco Esparza declaró haber buscado el cuerpo de su hermano para darle cristiana sepultura en el campo santo aledaño a la iglesia de San Fernando; fue acompañado en

\footnotetext{
${ }^{12}$ El testador "murió de fiebre" poco después de la edad de 75 años, y fue sepultado por el padre Refugio de la Garza el 26 de diciembre de 1835 . Véase San Fernando Burials, 1560, en Catholic Archives at San Antonio.

${ }^{13}$ Carta de Robert L. Tarin Jr. a Ray J. Esparza, 2 de diciembre de 1990, a su vez basada en Final Record Book A, p. 41, Spanish Archive. La carta y una transcripción del testamento se encuentran en DRTL, "From R. J. Esparza".
} 
este aserto por varios testigos. Enrique Esparza, un hijo de Gregorio, aclaró mucho después que "el entierro, como los demás incidentes de esa batalla, fue muy apresurado". Tanto, que al parecer no fue registrado oportunamente en los libros parroquiales. ${ }^{14}$

Según Francisco, en 1859 el cuerpo de Gregorio seguía sepultado en el campo santo, pero este desapareció unos meses después. Sobre su parte católica se erigió el hospital de Santa Rosa, y su parte protestante fue convertida en el parque Milam. Los cuerpos de la parte católica fueron trasladados al cementerio que ahora se llama San Fernando 1; excavaciones posteriores han continuado encontrando esporádicamente restos humanos debajo del hospital y en el parque. Ante esto, no es posible determinar qué sucedió exactamente con los restos de Gregorio Esparza. ${ }^{15}$

\footnotetext{
${ }^{14}$ En los Catholic Archives at San Antonio, revisé los registros de sepultura (San Fernando Burials) de marzo de 1836, sin encontrar el correspondiente a Gregorio Esparza. Sin embargo, una transcripción y traducción al inglés de dichos registros, que me proporcionó el Hermano Edward Loch, incluye el registro 1563, con el siguiente texto: "Mar. 6. ESPARZA, Gregorio, casado, padre de Enrique, héroe de El Álamo. Fue artillero y fue muerto en El Álamo mientras su familia veía. Único hombre a quien se dio sepultura católica. Todos los otros fueron quemados." Vistos el texto y el hecho de que existe otro registro con el mismo número 1563 datado el 4 de marzo de 1836 y correspondiente a un oficial mexicano, deduzco que el relativo a Gregorio Esparza fue agregado muy posteriormente a los hechos.

${ }^{15}$ Consultados el Hermano Edward Loch, de los Catholic Archives at San Antonio, y el señor Robert Cornejo, de los Catholic Cemeteries at San Antonio, estos no disponen de información al respecto.
}

\section{Gregorio Esparza en El Álamo:} testimonios judiciales

La República de Texas -y luego el estado estadunidense de Texas- otorgaba tierras a quienes hubieran residido en ella en los primeros años de su existencia, y -en mayor cuantía- a quienes hubieran combatido por su independencia. En consecuencia, Ana Salazar viuda de Esparza, fallecida en $1847,{ }^{16}$ y luego sus hijos Enrique, Manuel y Francisco, que para ese momento estaban viviendo en su rancho en el condado de Atascosa, solicitaron tierras en su calidad de herederos de Gregorio Esparza. ${ }^{17} \mathrm{Al}$ respecto, el 24 de abril de 1854 el ayudante general del Estado de Texas, Samuel S. Gillet, expidió un certificado en su favor, en el que asentó que:

Gregorio Esparza habiendo servido fiel y honorablemente en el ejército de la República de Texas, por el término de - meses desde el 3ro. de noviembre de 1835 hasta el 6to. día de marzo de 1836, y habiendo sido muerto en El Álamo, sus herederos tienen derecho a 1920 acres de tierra en recompensa. ${ }^{18}$

No obstante, en 1857 el Comisionado de Reclamaciones, James C. Wilson, anotó

\footnotetext{
${ }^{16}$ Véase San Fernando Burials, Catholic Archives at San Antonio, 1847, 89: “462. Ana Salazar, viuda de Gregorio Esparza. En veinte y dos de diciembre de 1847 yo el infrascrito enterré el cuerpo de Ana Salazar que murió el día precedente...".

${ }^{17}$ Los documentos se encuentran en Texas General Land Office (en adelante GLO), bajo el rótulo "G. Esparza”, exp. C/C 2558, y en Bexar County Courthouse Archives (en adelante BCC), Headright Records.

${ }^{18}$ GLO, rótulo "G. Esparza”, archivo 3-2. Grafía incierta: la fecha del certificado podría ser 1851 , y no 1854.
} 
"Registrado y rechazado" sobre el certificado referido. ${ }^{19}$ Los Esparza apelaron, y tiempo después el secretario de la Corte del condado de Béxar, Samuel S. Smith, recabó varios testimonios que ratificaron el papel de Gregorio Esparza en la independencia de Texas. ${ }^{20}$ El 13 de diciembre de 1858 el capitán don Manuel Flores, manifestó que:

Esparza había servido en la compañía de Seguín y como tal participado en la toma de Béxar en 1835, y señaló: "Es un hecho notoriamente conocido que Gregorio Esparza cayó en El Álamo con el coronel Travis. Yo lo conocía bien, y a mi retorno aquí después de la batalla de San Jacinto, todos me dijeron que Gregorio Esparza y otros habían caído en El Álamo, la verdad nunca ha sido puesta en duda.'

Por su lado, Gregorio Hernández testificó el 27 de diciembre de 1858 que:

Gregorio Esparza estuvo en el servicio militar de Texas en 1835 y 1836. Se unió al ejército en las cercanías de San Antonio en algún momento de la última parte de octubre de 1835, para la duración de la guerra. Sirvió desde ese tiempo hasta que fue muerto en El Álamo, marzo 6 de 1836. Estuvo en la

19 Ibid.

${ }^{20}$ Smith certificó que los testigos eran de su conocimiento personal, "hombres de credibilidad, ciudadanos de Texas y residentes del condado de Béxar"; agregó que los interrogatorios fueron conducidos en español, que el propio Smith redujo las respuestas al inglés escrito, y que tras leerlas a los deponentes, estos juraron que eran "verdaderas y correctas". Para la certificación y los varios testimonios que serán citados, véase GLO, Republic and State Collections, Court of Claims, 2558. compañía del capitán Juan N. Seguín, y con el coronel Travis. Estuvo en el servicio voluntario. Fue muerto en servicio. [...] Porque su esposa, sus hijos y sus relaciones me han dicho que ellos reconocieron su cuerpo luego de la lucha [y] lo reclamaron, lo obtuvieron, y le dieron cristiana sepultura. [...] Sé que el mencionado Gregorio Esparza estuvo en la toma de Béxar, porque entramos en dicha plaza juntos, y yo efectivamente lo vi participando en su reducción. [...] Sé que permaneció, porque lo vi en la capitulación [del general Cos] y después. Estuvo implicado en dicha acción todo el tiempo sobre el lado norte del pueblo.

Adicionalmente, Flores manifestó que él había sido sargento de ordenanza en la compañía de Seguín, y Hernández agregó que sabía todo esto por haber sido soldado raso en la misma; efectivamente, ambos figuran en las listas de tropas al mando del coronel Seguín. ${ }^{21}$ Pero, notablemente, Gregorio Esparza no está incluido en ellas, ni siquiera en la "Lista de los individuos de la compañía voluntaria de la municipalidad de Béxar que participaron en la toma de la ciudad de Béxar." ${ }^{22}$ Dada la impor-

\footnotetext{
${ }^{21}$ Daughters (Muster, 1986) enlista a las personas que se enrolaron en el ejército de Texas o participaron en hechos de armas de la revolución texana. En la página 255, bajo el encabezado "Bexar, Storming and Capture of, Continued", incluye a: "Gómez, Francisco", "Flores, Manuel” y "Flores, Manuel María”. Además, ambos Flores, padre e hijo, aparecen mencionados también en otras páginas -y por lo tanto compañías o eventos- de los Muster Rolls. Por otro lado, la activa participación del capitán Manuel Flores al frente de los grupos de tejanos que participaron en la revolución fue bien conocida en su época y está ampliamente documentada.

${ }^{22}$ Esta lista fue elaborada por Seguín en 1858, "en sustitución de la que se había quemado en la ofi-
} 
tancia de estas listas para el otorgamiento de recompensas, es dable pensar que el papel de Esparza haya sido tan modesto, o tal vez esporádico u ocasional, como para que Seguín haya omitido u olvidado mencionarlo. En este punto, cabe aclarar que la organizada por Juan Nepomuceno Seguín se contó entre las primeras compañías rebeldes, y fue una de las más exitosas en combate.

El 26 de agosto de 1859 Smith recabó dos testimonios más. Uno fue de Francisco Esparza, según quien:

su difunto hermano Gregorio Esparza había entrado como voluntario al servicio de Texas hacia mediados de octubre de 1835, y como tal soldado voluntario había entrado en San Antonio, con las fuerzas americanas, entre las mañanas del 5 y el 10 de diciembre de 1835; que permaneció en Béxar hasta el acercamiento del general Santa Anna, cuando entró en El Álamo, siendo muerto; que luego de la caída de El Álamo solicitó y obtuvo permiso del general Cos para tomar el cuerpo de su hermano y enterrarlo; que lo encontró en uno de los cuartos, habiendo recibido una bala de cañón en el pecho, y una herida de espada en el costado, y que en compañía de sus dos hermanos lo enterraron en el campo santo en el lado oeste del Arroyo de San Pedro, donde todavía reposaba [a la fecha de la deposición]. Añadió que su hermano en el momento de la toma de Béxar estaba bajo el comando del coronel Juan N. Seguín y del capitán don Manuel Flores, siendo un miembro de su compañía. Explicó que él mismo, Francisco, pertene-

cina del ayudante general”. Véase Seguín, Revolution, 1991, pp. 182-184. Los 22 o 23 años transcurridos desde los hechos pueden explicar omisiones en la misma. cía a la Compañía Presidial Local de Béxar, y que como los soldados de la compañía de El Álamo estaban bajo la capitulación del general Cos. Autorizados a permanecer en Béxar con sus familias, él permaneció con su familia, ya que allí había nacido y había siempre vivido; y que cuando Santa Anna arribó en febrero de 1836, dio órdenes de que todos aquellos que hubiesen sido los soldados locales a la capitulación del general Cos, debían mantenerse listos para unirse al ejército en servicio activo, pero que nunca los llamó para salir de sus casas. Finalizó diciendo que permaneció allí cuando el ejército de Santa Anna fue hacia el interior de Texas, teniendo a la fecha de su deposición 54 años de edad. ${ }^{23}$

El último testigo, Candelario Villanueva, ratificó el testimonio anterior, y aunque no aparece en las listas de las tropas al mando de Seguín ${ }^{24}$ añadió:

haber sido él mismo un miembro de la compañía del capitán J. N. Seguín en 1835 y 1836, al igual que Gregorio Esparza; que debido a que el coronel Seguín lo envió a cerrar su casa con llave, quedó en San Antonio y no en El Álamo; y que después de la caída del fuerte acudió al mismo, donde pudo ver a Francisco Esparza y sus hermanos tomar el cuerpo de Gregorio y llevárselo hacia el campo santo para su entierro.

Sopesando estos testimonios con conocimiento cercano en tiempo y lugar a los hechos, las autoridades texanas finalmente hicieron justicia. El 23 de mayo de 1860, un nuevo Comisionado de Reclamaciones

\footnotetext{
${ }^{23}$ Lo que se corresponde con el nacimiento de Francisco en 1804.

${ }^{24}$ Véase Daughters, Muster, 1986.
} 
escribió sobre el certificado ya mencionado: "Estoy satisfecho con las pruebas presentadas de las que el rechazo anterior fue impropio. Por consiguiente, lo apruebo." 25 Pero sólo a partir de 1868 lograron los herederos de Gregorio Esparza obtener título sobre las tierras solicitadas. ${ }^{26}$

\section{Francisco Esparza reclama tierras para sí mismo}

Francisco Esparza también logró tierras, basado en que había sido un residente leal de Texas al momento de su independencia y en los años inmediatamente posteriores.

En 1840 reclamó un certificado de segunda clase por 640 acres, presentando

${ }^{25}$ Anotación del comisionado Hutchkiss sobre el certificado que se encuentra en GLO, rótulo "Esparza", archivo 3-2.

${ }^{26}$ Véase Miller, Bounty, 1967, p. 253: "ESPARZA, GREGORIO (HEREDEROS) Los herederos de Gregorio Esparza recibieron del ayudante general (en adelante AG) el Certificado de Recompensa [Bounty Warrant] 1577 por 1920 acres el 24 de abril de 1854 por su servicio del 3 de noviembre de 1835 al 6 de marzo de 1836 cuando cayó en El Álamo. 316 acres en Bandera City fueron patentados a los herederos el 29 de septiembre de 1868. Patente 296, vol. 13, abst. 131, GLO, File Bexar Bty 1200, y 1351 acres en Bandera City fueron patentados a los herederos el 10 de abril de 1872. Patente 121, vol. 14, abst. 130, GLO, File Bexar Bty 1200. Sobre el balance no localizado, Certificado 17/230 de 1577, 253 acres en el condado de Béxar fueron patentados a los herederos el 22 de abril de 1874. Patente 256, vol. 14, abst. 226, GLO, File Bexar Bty 1515”, y p. 764: “ESPARZA, GREGORIO (HEREDEROS) recibieron del AG certificado de donación 572 por 640 acres el 24 de abril de 1854 por haber caído en El Álamo. 525 acres en el condado Hays fueron patentados a los herederos el 27 de octubre de 1876. Patente 86, vol. 4, abst. 169, GLO, File Trans Don 762." dos testigos, Juan Urrutia y Domingo Pérez, que coincidieron en que "el reclamante vino a esta República hace un año [o sea, en 1839, lo que no coincide con los hechos] [...] es un hombre casado y cabeza de una familia”. ${ }^{27}$ En 1845 se le otorgaron los acres solicitados, cuya ubicación, medición y patentamiento se completó el 11 de marzo de 1846. Al día siguiente, las vendió. ${ }^{28}$

En 1860 volvió a reclamar tierras, en este caso un certificado de primera clase, que se otorgaban a quienes habían residido en Texas al momento de su independencia, o sea entre 1835 y 1836 . El argumento del peticionario constituye una síntesis de su vida, y ratifica una vez más que su hermano Gregorio había muerto en El Álamo. Francisco Esparza declaró: ${ }^{29}$

haber nacido en San Antonio de padres texanos el 31 de marzo de 1806 [sic, por 28 de marzo de 1804], que había permanecido en San Antonio hasta 1829, fecha en que casó con Ana [sic, por María Josefa] Flores, de dicho lugar, y que a la fecha de la declaración de independencia [1836] era residente y ciudadano del país [Texas], un hombre casado con tres hijos y jefe de una familia[...] que en dicho momento no dejó el país en la primavera de 1836 para evitar participar en la lucha, que no se rehusó a participar y que no ayudó o asistió al enemigo. Por el contrario, había sido un buen y confiable amigo de la causa de Texas, y sólo sus

${ }^{27}$ Véase BCC, Headright Record I, p. 159, 2 de enero de 1840, entrada 113.

${ }^{28}$ Véase BCC, vol. C-2 Record, pp. 296-298, entradas 266 y 267.

29 Para este y demás testimonios de dicho año, véase BCC, Headright Record I, pp. 258-260, 24 de agosto de 1860, entrada 54. 
obligaciones hacia sus jóvenes hijos le habían impedido voluntariamente tomar una activa parte en la lucha por la independencia. Tanto fueron el peticionante y su hermano amigos de esa causa, que Gregorio Esparza murió en El Álamo.

El peticionante concibe que tenía justo derecho a un Certificado de Primera Clase por una legua y una labor de tierra, lo cual nunca había solicitado ni recibido debido a que era ignorante de su derecho así como del idioma inglés. Fue sólo mucho después de que las Cortes del condado fueron cerradas a reclamos de primera clase que se le dijo que tenía derecho a algunas tierras, y como en ese momento la ley en vigor concedía 640 acres a los hombres casados, sólo un certificado de esa clase le fue entregado, por lo que pedía se le concediese el remanente.

Dos testigos, Antonio Menchaca y Francisco Gómez, confirmaron sus dichos. El primero además afirmó que Francisco Esparza había nacido en 1806 [sic, por 1804], siendo una persona blanca, libre de sangre mexicana y no africana. ${ }^{30}$ Gómez, por su parte, agregó que había conocido a Francisco Esparza en 1826, que en 1827 había ido con este a Nacogdoches, y que habían permanecido allí por un año. Tiempo después de volver juntos a San Antonio, Francisco Esparza había casado con María Flores; y añadió que según su conocimiento, el peticionario nunca había recibido las tierras a las que tenía derecho, ni ninguna parte de ellas. ${ }^{31} \mathrm{El}$ autor no ha podido determinar el resultado de esta segunda petición.

${ }^{30}$ Recuérdese que Francisco Esparza era mestizo, probablemente de contextura oscura.

${ }^{31}$ Véase BCC, Headright Record I, pp. 258-260, 24 de agosto de 1860, entrada 54.
Estas deposiciones son inconsistentes en parte. En su reclamo de 1840, Francisco Esparza probablemente habría querido ocultar su participación en la Compañía Presidial, y por eso manifestó ser un recién llegado, lo que los registros históricos demuestran no ser cierto; tal vez por eso -apoyado por sus testigos- declaró haber llegado a Texas en 1839. Dos décadas después podría haberse sentido suficientemente confiado dentro de la Texas ya estadunidense como para señalar su verdadero papel en los hechos de 1836. Así, en su testimonio de 1859 a favor de sus sobrinos, sostuvo que para la fecha de la toma de El Álamo pertenecía a la mexicana Compañía Presidial de San Antonio, aunque sin haber tomado las armas contra Texas, y que había recogido y enterrado los restos de su hermano. Y en 1860 agregó que había nacido en San Antonio, que en 1836 residía en Texas, que había sido amigo de la causa texana, y que su hermano había muerto en El Álamo.

\section{EN 1901, ENRIQUE ESPARZA REVELA EL PAPEL DE SU PADRE EN El Álamo}

Adina de Zavala, nieta de Lorenzo de Zavala, el primer vicepresidente de la Texas independiente, fundó a fines del siglo XIX la asociación Daughters of the Republic of Texas (Hijas de la República de Texas). En 1901 conoció a un hijo de Gregorio Esparza, Enrique, quien había regresado a San Antonio después de décadas de residir en el condado de Atascosa. Interesada en destacar la participación de personas de linaje mexicano en la independencia de Texas, la señorita De Zavala promovió la publicación de una narración de Enrique Esparza. Esta y subsiguientes 
narraciones coinciden en lo esencial: cuando Santa Anna llegó a San Antonio, Gregorio Esparza, a sugerencia de su amigo y compadre John W. Smith, se refugió con su familia en El Álamo, donde murió durante el asalto final de las tropas mexicanas; Francisco Esparza solicitó permiso para enterrarlo en el campo santo de la iglesia de San Fernando; la viuda de Gregorio fue recibida al día siguiente por Santa Anna, quien le dio alguna ayuda económica. En todo lo demás, hay variantes que pueden atribuirse a la avanzada edad del narrador, a los muchos años transcurridos, a las dificultades idiomáticas entre el narrador y el entrevistador, y también al embellecimiento que los entrevistadores pueden haber hecho de la historia.

La primera publicación de estos relatos tuvo lugar en el San Antonio Light el 10 de noviembre de 1901. Tras mencionar el papel desempeñado por Adina de Zavala en el "descubrimiento" de Enrique Esparza, el entrevistador escribe:

"[Enrique Esparza] Es un mexicano y ha mantenido silencio durante todos estos años porque no conocía el valor de su testimonio ni pensó nada acerca de la famosa batalla a través de la cual pasó cuando recibió su bautismo de sangre y fuego. Fue sólo accidentalmente que fue descubierto por la señorita De Zavala, y ella considera su hallazgo como uno remarcable...

"Don Enrique Esparza [...] fue testigo ocular de algunas de las más trágicas escenas del siglo pasado. Era un niño de ocho años al momento de la masacre de El Álamo. Sus ojos son brillantes y su memoria clara. Tuvo la ventaja de una buena educación y es sumamente interesante.

"Su padre, también, vivió en días terribles; fue capturado cuando niño por los indios comanches y fue rescatado, ya cre- cido, y llevado de vuelta a San Antonio, por el coronel Ruiz. Las familias de ambos padres de Esparza eran gente inteligente y acomodada, que eligió luchar por la libertad y la Constitución de 1824.

"Temprano en 1836 fueron avisados por cartas del vicepresidente De Zavala, a través del capitán Rojo, de que las hordas mexicanas estaban llegando, y aconsejados de que llevasen sus familias a un lugar seguro. En la mañana del 22 de febrero John W. Smith, uno de los exploradores, galopó hasta la casa de los Esparza llevando la noticia de que Santa Anna estaba cerca, y que estaría sobre ellos por la noche. ¿Qué podrían ellos hacer?, fue la pregunta. ¡Huir no podrían! ¿Deberían tratar de esconderse o ir a la fortaleza de El Álamo? La madre se decidió por El Álamo, porque allí su marido estaría luchando por la libertad. Hasta allí llevaron en sus brazos sus más preciosas posesiones, yendo y viniendo muchas veces, hasta que a la caída del sol la madre, la señora Anita Esparza, con sus últimos paquetes y su pequeña hija y cuatro hijos, cruzó el puente sobre la acequia hacia el patio de El Álamo justo cuando se escuchaba el sonido de la trompeta y el ruido del ejército de Santa Anna. Dentro del patio de El Álamo había también otros refugiados que se habían salvado: la señora Alsbury y un hijo y su hermana, Gertrudes Navarro; la señora Concepción Losoya, su hija y dos hijos; Victoriana de Salina y tres niñas pequeñas; la señora Dickinson y su bebé (hasta el momento creídos de ser los únicos que escaparon vivos); y una anciana mujer llamada Petra.

${ }_{i}$ No hay lengua que pueda describir el terror y el horror de esa espantosa última lucha! Las mujeres y los niños estaban paralizados de terror y desvanecían de 
hambre cuando los soldados mexicanos irrumpieron luego de la caída de El Álamo. Un pobre paralítico incapaz de hablarles y decirles que él no era un combatiente fue asesinado delante de sus ojos, como también lo fue un joven que había sido capturado algún tiempo antes y que continuaba en El Álamo. Un joven, Brigidio Guerrero, se salvó al alcanzar a decir que él no era un texano, sino un prisionero de los texanos.

"Un oficial mexicano, relacionado con algunos de los refugiados, llegó justo a tiempo de salvar a las mujeres y los niños, aunque estos fueron sujetos de terrible trato y horrible abuso. Finalmente, alguien obtuvo salvoconducto para ellos alrededor de las dos de la mañana del 7, hasta la casa del gobernador Múzquiz, ${ }^{32}$ en la plaza principal. Allí los sirvientes de Múzquiz sirvieron café a los hambrientos prisioneros. Al clarear el día fueron requeridos de ir ante Santa Anna y presentar su voto de lealtad. Santa Anna en persona dio luego a cada madre una cobija y dos dólares. Las únicas dos personas que escaparon de esta humillación adicional fueron las dos hijas de Navarro, que fueron sonsacadas por su padre [tío, en realidad], José Antonio Navarro. El cuerpo del padre de Esparza, que había sido masacrado junto con otros texanos, fue recuperado por su hermano que estaba en el ejército mexicano y fue enterrado en el campo santo de San Fernando y así tiene la distinción de haber sido el único texano que escapó de la pira funeraria.

"La señorita De Zavala piensa que con lo que pueda espigar de Esparza, podrá

\footnotetext{
${ }^{32}$ Se refiere a Ramón Múzquiz; no se confunda con Melchor Múzquiz, igualmente coahuilense, que fue presidente de México en 1832.
}

añadir mucha información valiosa a la historia acerca de la caída de El Álamo, de la cual muy poco es ahora auténticamente conocido. Ninguna historia de Texas menciona el escape de nadie de El Álamo excepto el de la señora Dickinson y su hijo, y el descubrimiento de la dama de San Antonio es de gran valor." 33

La publicación citada contiene obvias inexactitudes que pueden deberse más a la señorita De Zavala o al periodista transcriptor que al narrador Enrique Esparza. Los Esparza no eran "gente acomodada". Lorenzo de Zavala no era vicepresidente en febrero/marzo de 1836, y difícilmente hubiese podido avisar que Santa Anna ya estaba llegando, siendo que su arribo tomó desprevenidos a los independentistas. El capitán Rojo probablemente era John W. Smith, conocido como "Red" por su cabello rojizo. Como sea, lo cierto es que -como bien preveía la señorita De Zavalael relato despertó interés por la participación de los tejanos en la batalla de El Álamo y en la independencia de Texas en general. En el anexo 2 se extractan y comentan relatos ulteriores de Enrique Esparza, que coinciden en lo esencial con este primero pero varían considerablemente en los detalles.

\section{EVALUACIÓN CRÍTICA DE LAS EVIDENCIAS}

Actas de matrimonio, fes de bautismo y registros censales comprueban que Gregorio y Francisco Esparza nacieron y vivieron en San Antonio, y que allí formaron sus familias de clase trabajadora: el marido de su madre, su medio hermano Francis62-66.

${ }^{33}$ Reproducido en Matovina, Alamo, 1998, pp. 
co y el propio Gregorio fueron registrados en los censos como "jornaleros". En particular Gregorio, hijo de madre viuda y padre desconocido y a quien se menciona como "sirviente" y deudor, pudo haber tenido una condición social humilde. Es de suponer que no hablaba inglés, como tampoco lo hacía su hermano Francisco. Lo más seguro es que fuese analfabeta.

La evidencia sobre la participación de Gregorio en el movimiento independentista texano procede exclusivamente de testimonios de su hermano Francisco y de testigos amigables, de las narraciones de su hijo Enrique, y de la historia oral cultivada por sus descendientes. O sea, no hay corroboración documental en fuentes independientes a la familia Esparza y su círculo. ${ }^{34}$ Esto no es inusual: ha habido constante investigación y discusión historiográfica para tratar de determinar, sin lograrlo del todo, quiénes fueron exactamente los defensores de El Álamo caídos en batalla.

Ya se explicó más arriba que no se conservan registros de que Gregorio Esparza hubiese participado en la compañía del coronel Seguín, o de que fuese sepultado en el campo santo de San Fernando. Tampoco figuró Gregorio Esparza en las listas de defensores de El Âlamo caídos en batalla publicadas durante el siglo XIX, aunque sí en las revisadas en el siglo Xx. ${ }^{35}$ Los monumentos levantados en San An-

\footnotetext{
${ }^{34}$ Excepto el registro de la sepultura de Gregorio Esparza mencionado en la nota 14, que parece haber sido agregado con posterioridad a los hechos.

${ }^{35} \mathrm{La}$ primera lista fue publicada por el periódico Telegraph and Texas Register el 24 de marzo de 1836, incluyendo sólo 112 nombres y aclarando que podría contener errores; la omisión es particularmente significativa, pues la elaboración de la lista fue supervisada por John W. Smith, el amigo de la familia
}

tonio y Austin en el siglo Xx incluyen a un Esparza, sin nombre de pila. Por su lado, la reconocida investigadora Amelia Williams publicó en 1933-1934 la que se considera la lista quasidefinitiva de los caídos, incluyendo en ella a Gregorio Esparza. ${ }^{36}$

Un puñado de no combatientes que sobrevivieron a la batalla narraron sus experiencias, publicadas durante el siglo XIX en forma muy indirecta por terceras personas: la señora Susanna Hanning Dickinson, la señora Juana Navarro Alsbury, Brigidio Guerrero, y Joe, un esclavo negro. Ninguno de sus relatos publicados menciona a Gregorio Esparza, esposa o hijos. Es de suponer que los sobrevivientes enfatizaron sus impresiones más fuertes, o respondieron a preguntas directas de sus entrevistadores; la presencia de la familia Esparza en el fuerte no habría tenido nada de impresionante, y los entrevistadores no tenían motivos para preguntar por ella, ya que sólo en el siglo XX se supo de la misma. Por el contrario, Enri-

Esparza que les aconsejó refugiarse en El Álamo. Véase Williams, "Critical”, 1934, parte v, p. 237.

${ }^{36} \mathrm{Ibid}$., p. 257 , incluye la siguiente ficha: "ESPARZA, GREGORIO: edad, 33; rango, soldado; nativo y residente de San Antonio. Fuentes: Béxar, 1183; Travis, 762; I Béxar, 682; Solicitudes a la Corte de Reclamaciones, núm. 572, Archivo (D-G). Este último documento citado muestra llanamente que lograr las concesiones de tierras debidas por sus servicios era más difícil para los mexicanos que participaron en las batallas de la revolución texana, que para otros. Esparza fue uno de los soldados de Juan N. Seguín. Su familia, esposa y cuatro hijos, estaban en El Álamo cuando este cayó. Él tenía un hermano en el ejército de Santa Anna, el cual, con otros amigos, pidió a Santa Anna el cuerpo sin vida de su amigo. Santa Anna accedió a la petición, y su cuerpo no fue quemado con el resto de las víctimas, sino que fue llevado por sus amigos y sepultado." 
que Esparza sí nombró a los narradores, seguramente a pregunta expresa de sus entrevistadores, que conocían la existencia de esos otros supervivientes.

Hay otras posibles explicaciones particulares para que estas narraciones omitiesen a los Esparza. Por ejemplo, la señora Dickinson aseguró que su propio hijo "fue el único niño en el fuerte", y que ella misma, junto con la esposa y cuñada del doctor Horace Alsbury, "fueron las únicas mujeres en el fuerte". ${ }^{37}$ En coherencia con este dicho, la señora Alsbury afirmó que ella, su hermana y la señora Dickinson "eran las únicas mujeres en la guarnición"; 38 pero en otro momento reconoció que "había en El Álamo gente que no vi". ${ }^{39}$ Ahora bien, la señora Dickinson "odiaba a los mexicanos", conforme a otra testigo; ${ }^{40}$ y según Enrique Esparza, la señora Alsbury no quería admitir a su madre Ana Salazar como una conocida, e incluso luego de la caída del fuerte no le dirigía la palabra. ${ }^{41}$ Esto sugiere que las señoras Dickinson y Navarro Alsbury creían estar en un nivel social superior al de los Esparza, a los que no valía la pena mencionar en caso de que efectivamente los hubiesen visto. Brigidio Guerrero, por su lado, dejó una petición de tierras por servicios prestados en El Álamo, ${ }^{42}$ en el que manifestó haber sobrevivido por

${ }^{37}$ Véase Groneman, Eyewitness, 1996, p. 74.

${ }^{38}$ Matovina, Alamo, 1998, p. 33.

${ }^{39}$ Ibid., p. 46.

${ }^{40}$ Véase a Andrea Castañón de Villanueva, en ibid., p. 107.

${ }^{41}$ Dice Enrique Esparza: "La señora Melton [por Juana Navarro Alsbury], que nunca había aceptado a mi madre como una conocida y que era considerada una aristócrata...". Véase ibid., pp. 71-72.

${ }^{42}$ Ibid., pp. 36-37. ocultarse en el último momento, lo que es coherente con la narración de Enrique Esparza. El negro Joe, que había sido esclavo del coronel Travis, dijo que "había varios negros y algunas mujeres mexicanas en el fuerte", ${ }^{43}$ mencionando por nombre sólo a las hermanas Navarro, lo cual no confirma ni contradice los relatos de Enrique Esparza.

Otra narradora fue Andrea Castañón de Villanueva, a la cual Enrique Esparza dijo no recordar haberla visto en el fuerte. ${ }^{44}$ Más conocida como "Madame Candelaria", por haberse casado con Candelario Villanueva ${ }^{45}$ sus relatos fueron recogidos y publicados por personas que dudaban de su veracidad. ${ }^{46}$ No mencionan ni a los Esparza ni al propio Villanueva, posiblemente por omisión de la narradora o bien por decisión de sus transcriptores. ${ }^{47}$

Tampoco las fuentes mexicanas ${ }^{48}$ mencionan a Gregorio o Francisco Esparza, ni a persona alguna que pudiese haber estado en posiciones similares a las desempeñadas por ellos y sus familias. Por cierto, el lado

${ }^{43}$ Groneman, Eyewitness, 1996, pp. 26-27.

${ }^{44}$ Dice Enrique Esparza: "No recuerdo haber visto allí a Madam Candelaria”. Véase Matovina, Alamo, 1998, p. 83.

${ }^{45}$ Quien, como se recordará, fue testigo de Francisco Esparza y dijo haber servido a las órdenes de Seguín.

${ }^{46}$ Su presencia en la caída del fuerte es dudosa; parece cierto que acudió varias veces a él para cuidar a los enfermos y heridos. En 1891 el estado de Texas le otorgó una pensión por este servicio prestado.

${ }^{47}$ Véase Matovina, Alamo, 1998, pp. 12, 51-53 y 57-62, y Groneman, Eyewitness, 1996, pp. 107-109, 110 y $122-127$.

48 Véase Santa Anna, "Informe”, 1973, vol. 5, pp. 11 y ss.; Filisola, Materiales, 1968; Pena, Santa Anna, 1997; Becerra, Mexican, 1980, y Asbury, "Private", 1944. 
mexicano quería destacar su victoria y lamentar sus propias bajas, y no detallar minucias tocantes a uno de los muchos vencidos y caídos, a los cuales por añadidura consideraban traidores.

En suma, los dichos de Francisco Esparza y sus testigos ante los tribunales, y los de Enrique Esparza a la prensa, carecen de corroboración documental por fuentes ajenas a su familia y en torno directo, y la participación de Gregorio Esparza en el movimiento independentista no consta en ninguna otra fuente de la época.

Sin embargo, un elemento central da credibilidad a su historia: el que los tribunales de la Texas estadunidense hayan concedido tierras a sus herederos. Las resoluciones judiciales a favor de sus hijos dan por sentado que Gregorio Esparza se unió a la causa independentista, y que murió en El Álamo combatiendo por ella. Su unión a los independentistas demuestra el hecho mismo de haberse refugiado en El Álamo; de lo contrario, podría haberse quedado tranquilamente en su casa, como hicieron su hermano Francisco y la gran mayoría de los habitantes de San Antonio de origen mexicano. ${ }^{49}$ Sobre las circunstancias precisas de su muerte, poco se sabe además de lo dicho por su hijo Enrique, a quien algunos periodistas hacen decir que su padre salió a luchar y ya no lo volvió a ver, y otros que lo vio morir junto con Travis sobre el techo de la iglesia de El Álamo.

${ }^{49} \mathrm{Al}$ respecto, el coronel Travis escribió: "los ciudadanos de esta municipalidad son todos nuestros enemigos, excepto [...] tres mexicanos que tenemos ahora en el fuerte". Véase Gronemann, Eyewitness, 1996, p. 11.

\section{REFLEXIONES FINALES}

Ante el rápido desarrollo de los acontecimientos, en 1835-1836 la comunidad tejana se vio dividida en bandos opuestos. Con agudeza señala un historiador: "Como muchos de los méxico-americanos de hoy, los tejanos del siglo XIX se sintieron presionados a elegir entre su Texas nativa y su madre patria cultural mexicana." ${ }^{50}$ Continúa el historiador citando:

Aunque amigos, vecinos e incluso familias [como los Esparza] se vieron divididos entre las fuerzas de México, las fuerzas de Texas y la posición de neutralidad, los tres grupos continuaron formando una comunidad sorprendentemente cohesionada en San Antonio [...] Estos signos de unidad entre los tejanos de San Antonio reflejan su historia como un grupo relativamente homogéneo de pobladores [...] Reflejan también la respuesta tejana al dilema de escoger lado durante la revolución texana. Aunque algunos tejanos locales apoyaron los bandos mexicano o texano, al parecer su lealtad más fuerte fue hacia sus conciudadanos de San Antonio, con quienes habían compartido una historia común y un predicamento común mientras la guerra asolaba su pueblo natal. Conscientemente o no, esta lealtad de grupo de los tejanos de San Antonio modeló su identidad como un pueblo distinto de su contraparte mexicana al sur del río Grande, tanto como de sus vecinos angloamericanos en Texas. ${ }^{51}$

Existen algunos ejemplos notorios. El gobernador Múzquiz, fiel a México, tras la

\footnotetext{
${ }^{50}$ Matovina, Alamo, 1998, p. 122.

${ }^{51}$ Ibid., pp. 123-124.
} 
independencia abandonó Texas y se estableció en Coahuila, de donde era oriundo. Por el contrario, Lorenzo de Zavala fue nombrado vicepresidente de la República de Texas, ${ }^{52}$ y Juan Antonio Navarro sería honrado bautizando un condado de Texas con su apellido. ${ }^{53}$ En un punto intermedio, la vida del coronel Seguín ${ }^{54}$ es ilustrativa del desgarramiento de lealtades que sufrieron algunos tejanos. Fue héroe de guerra, legislador y juez en la Texas independiente. En 1842, sintiéndose marginado y hasta amenazado, optó por regresar a México. Condenado por traición, fue liberado a cambio de que participase en una expedición que en ese mismo año trató infructuosamente de recapturar Texas. Durante la invasión estadunidense a México, de 1846 a 1848, combatió una vez más del lado mexicano. En 1848 retornó a Texas y continuó su carrera política y como ranchero. En 1883 se estableció en Nuevo Laredo, Tamaulipas, donde su hijo era presidente municipal; allí murió en 1890. Texas lo honró dándole su apellido a una ciudad situada 50 kilómetros al este de San Antonio.

En este contexto, se entiende mejor la actuación de los Esparza. ¿Se habrán enfrentado directamente en combate am-

${ }^{52}$ De Zavala fue un pensador y dirigente liberal mexicano, signatario de la Constitución de 1824, gobernador del Estado de México y embajador mexicano en París, que se había asentado como colonizador en Texas. Falleció en 1836.

53 Navarro fue constituyente y legislador de la Texas independiente; en 1840 fue capturado en Nuevo México por tropas mexicanas y condenado a prisión perpetua; amnistiado en 1845 , volvió a Texas y continuó su carrera política.

${ }^{54}$ Como curiosidad histórica, vale mencionar que estaba emparentado con uno de los mayores héroes mexicanos, el general Ignacio Zaragoza Seguín. bos hermanos? Potencialmente sí en diciembre de 1835, cuando Gregorio entró a San Antonio con los rebeldes y Francisco era miembro de la guarnición local mexicana. Pero definitivamente no en la toma de El Álamo en marzo de 1836, en la que Francisco no combatió. ${ }^{55}$

En cuanto a sus respectivas motivaciones, la participación de Francisco en el lado mexicano tenía raíces añejas. Resulta razonable suponer que se había enrolado -hacia 1828- en la Compañía Presidial de San Antonio como un medio de subsistencia; y que por lo mismo en 1835-1836 continuaba formando parte de las tropas locales mexicanas. Pero, ¿qué habrá motivado a su hermano Gregorio a unirse a la rebelión texana? Es dable que haya tenido razones político-ideológicas: oponerse al centralismo y autoritarismo de Santa Anna, que no eran bienvenidos entre los tejanos de la época, y en lo cual puede haberlo influido la familia Zambrano, que se inclinaba por el independentismo. ${ }^{56}$ De hecho, los rebeldes texanos habían declarado en un principio que luchaban por restablecer la Constitución mexicana de 1824; y en el fuerte de El Álamo enarbolaron la bandera mexicana cruzada con la cifra "1824". Es más verosímil que tuviese afinidad con los anglos, como lo sugiere su

${ }^{55}$ Ninguna de las fuentes mexicanas citadas en la nota 48 indica que las tropas presidiales (locales), de las que Francisco Esparza formaba parte, hubiesen participado en el asalto a El Álamo.

${ }^{56}$ El testador José María Zambrano estaba emparentado con Juan Zambrano, prominente ciudadano de San Antonio sobre quien pesaba una orden de arresto emitida por autoridades mexicanas, en cumplimiento de la cual fue detenido, enviado al interior, y presumiblemente ejecutado. Véase Rendon, Viva, 1985, p. 16. 
amistad con su compadre John William Smith, quien tuvo destacado papel en la rebelión. ${ }^{57}$ Más verosímil todavía es que haya sido su apremiante situación económica lo que lo impulsó a tomar las armas, con la esperanza de obtener tierras como recompensa.
Por la combinación de razones que sea, lo cierto es que Gregorio Esparza se sumó al bando texano. Fue un hombre ordinario que hizo algo extraordinario: dio su vida por una causa en la que creía. Por ello, recibió -aunque fuese de manera póstuma- justicia, tierras y honor.

${ }^{57}$ Smith destacó como mensajero en la batalla de San Jacinto, y colaboró en compilar la primera lista de caídos en El Álamo (en la cual no incluyó a Gregorio Esparza). Fue alcalde de San Antonio y senador de Texas, entre otros muchos cargos públicos que ocupó tras la independencia. 


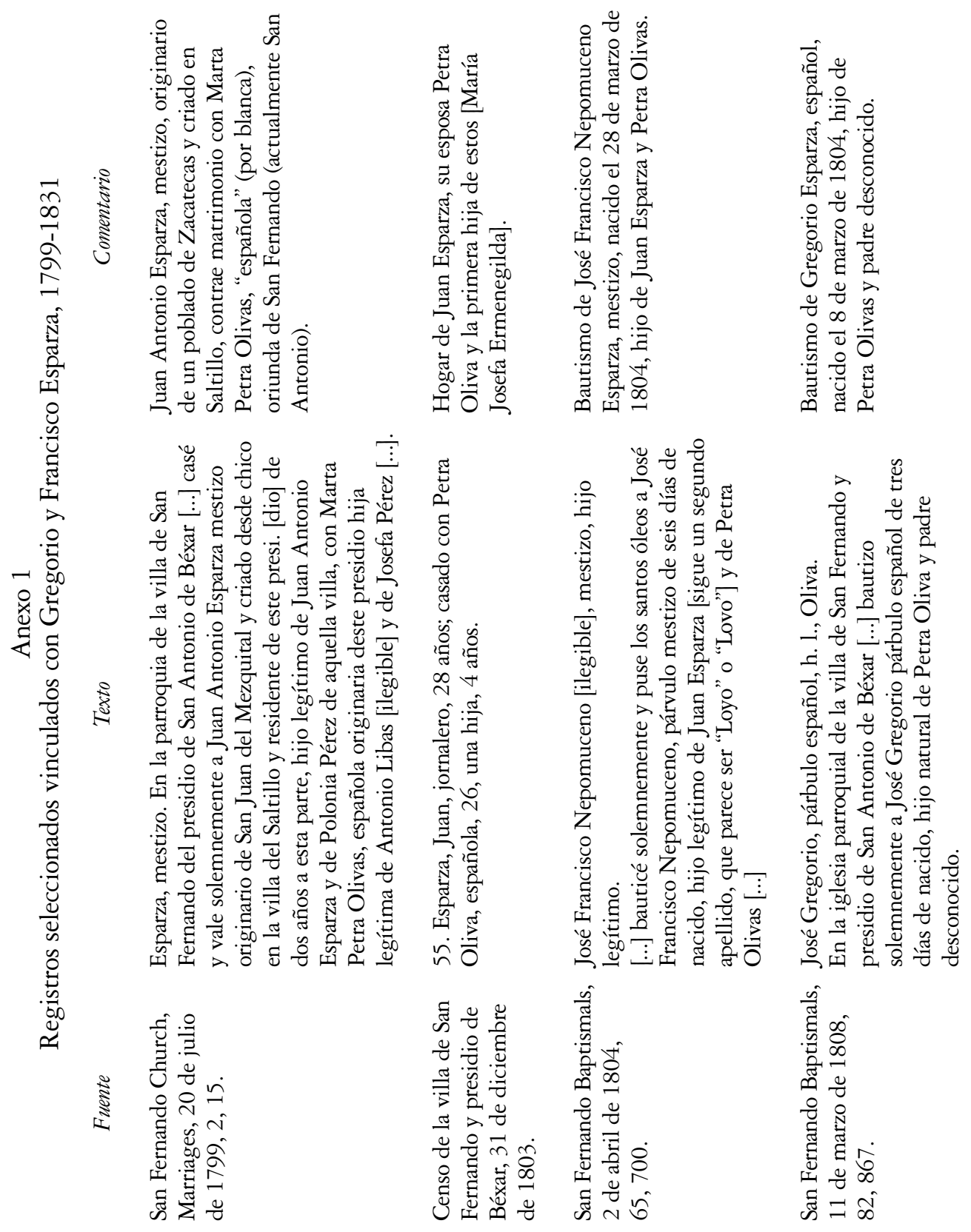




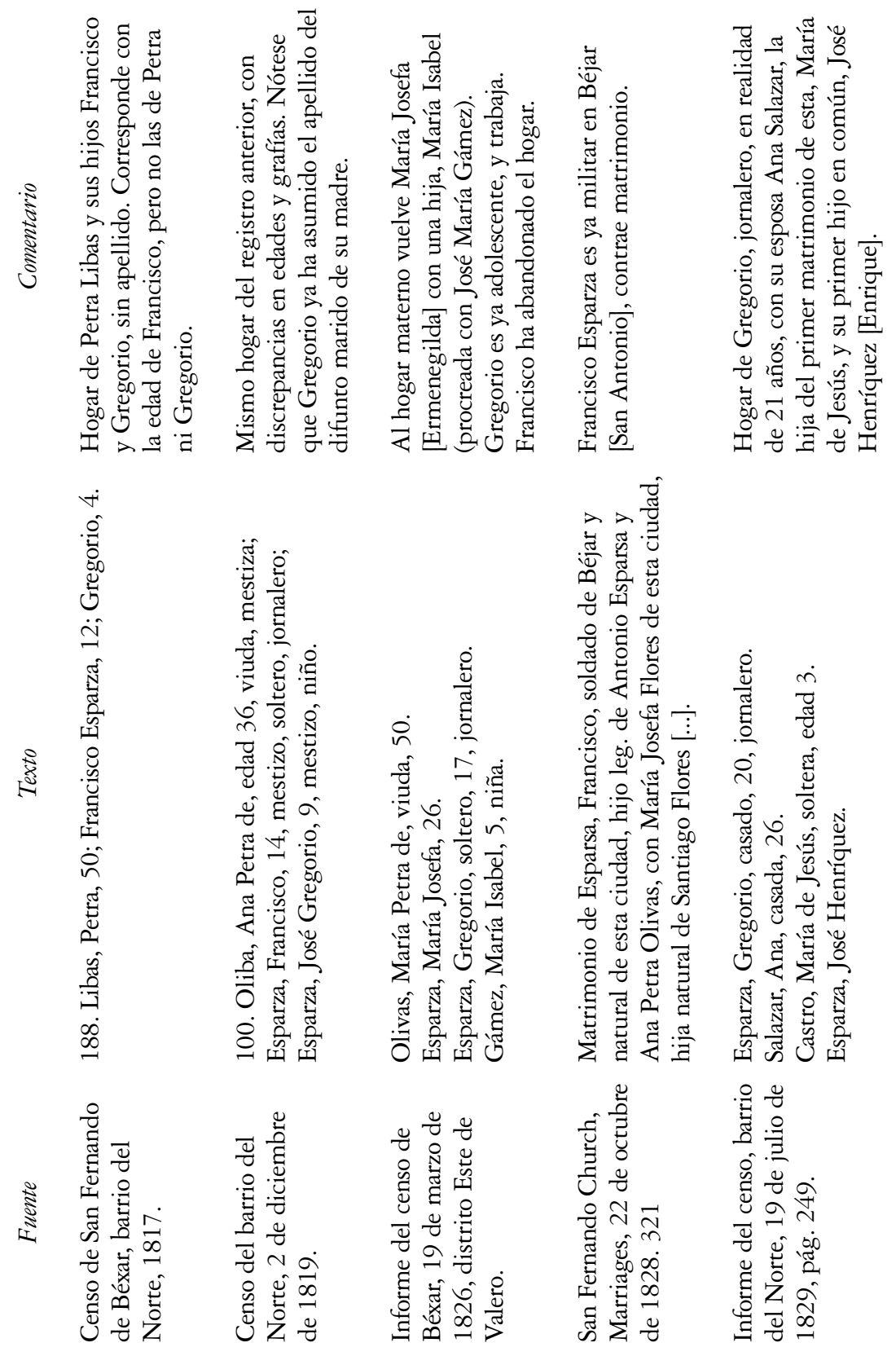




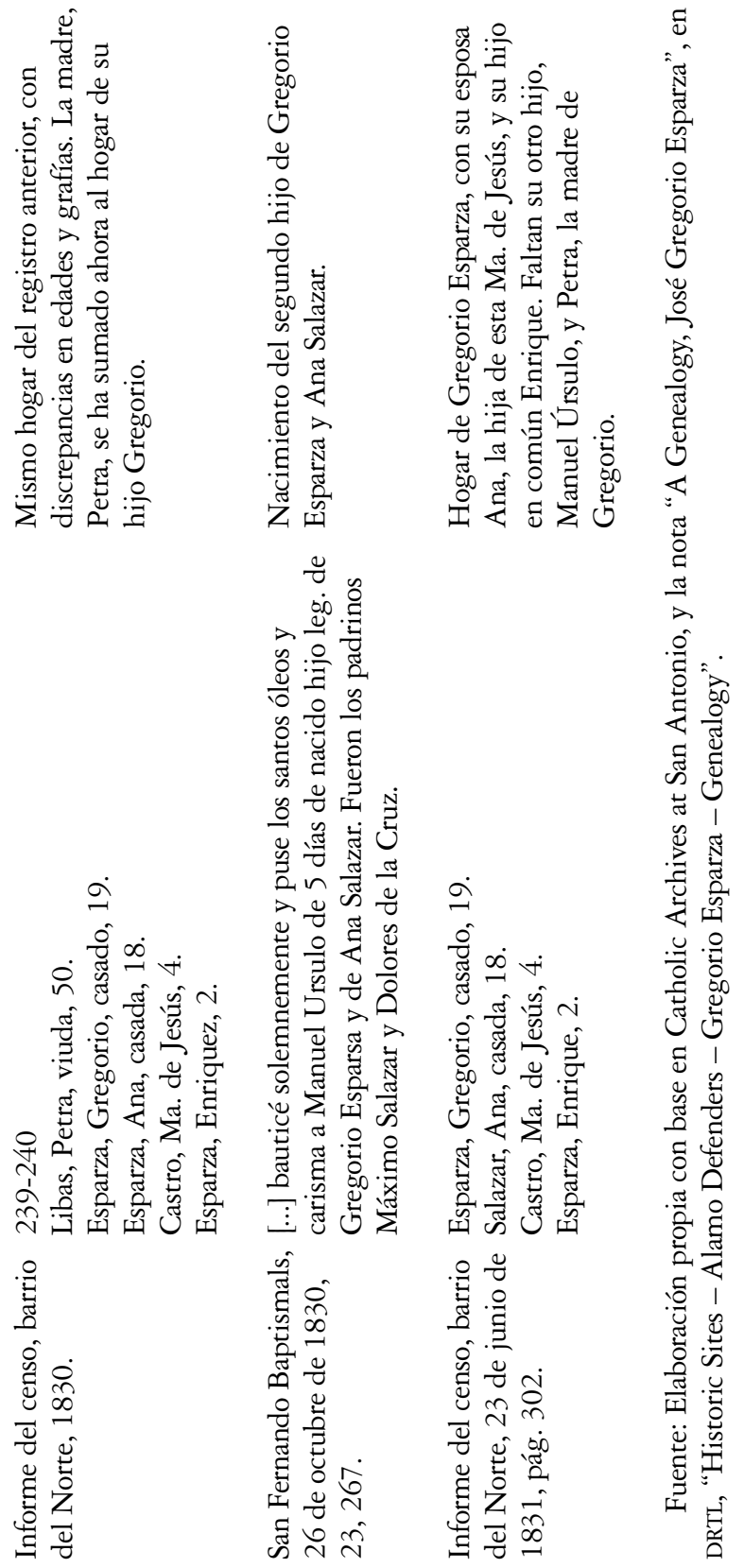


ANEXO 2. NARRACIONES FAMILIARES SOBRE GREGORIO Y FRANCISCO ESPARZA

Tras el relato original publicado en 1901, Enrique Esparza fue entrevistado varias veces respecto de la caída de El Álamo de 1836. A continuación se extractan y comentan en orden cronológico dichas entrevistas y relatos.

\section{Entrevista de 1902}

Una publicación de 1902 incluye entre los sobrevivientes enviados a la casa de Múzquiz a una señora Melton (que en opinión del autor, fue en realidad la señora Juana Navarro Alsbury). Aquí, Enrique Esparza aparece diciendo:

Mi padre, Gregorio Esparza, perteneció a la compañía de Benavides en el ejército americano y yo pienso que fue en febrero de 1836 que se ordenó a la compañía ir a Goliad. Ya estaban en Goliad cuando se ordenó a mi padre regresar, solo, a San Antonio, ¿para qué?, no lo sé. Cuando llegó aquí, había rumores de que Santa Anna estaba en camino hacia aquí y muchos residentes enviaron lejos a sus familias. Uno de los amigos de mi padre le dijo que podría tener una carreta y una yunta y todas las provisiones necesarias para un viaje, si él quería sacar a su familia [...]

Mi padre decidió aceptar la oferta y mudar la familia a San Felipe. Todo estaba listo cuando una mañana el señor W. Smith, que era padrino de mi hermano más chico, vino a nuestra casa en la calle Flores Norte [...] y dijo a mi madre que le dijese a mi padre cuando viniese, que Santa Anna había arribado. Cuando vino mi padre, mi madre le preguntó qué iba a hacer [...]
"Bien, yo me voy al fuerte", dijo mi padre.

"Bien, si tú vas, yo también voy, y toda la familia también" [...]

En la primera noche una compañía de la que mi padre era parte salió y capturó algunos prisioneros [...]

Recuerdo a Crockett [...] Los mexicanos lo llamaban don Benito [...] También recuerdo haber escuchado los nombres de Travis y Bowie, pero que yo sepa nunca vi a ninguno de los dos $[\ldots]^{58}$

En la última noche mi padre no estaba afuera, sino que él y mi madre estaban durmiendo juntos en los cuarteles. Alrededor de las dos de la mañana hubo un gran tiroteo y fuego en la esquina noroeste del fuerte y escuché a mi madre decir: "Gregorio, los soldados han saltado la barda. La lucha ha comenzado."

Se levantó y tomó sus armas y salió a la lucha. Nunca lo volví a ver. Mi tío me dijo después que Santa Anna le dio permiso para tomar el cuerpo de mi padre y que lo encontró allí donde la lucha había sido más concentrada. ${ }^{59}$

\section{La entrevista de 1907}

Una nota mucho más extensa fue publicada en 1907 bajo la firma de Charles Merrit Barnes. Cambian en este las circunstancias del ingreso de los Esparza a El Álamo, así como otros detalles:

${ }^{58}$ David Crocket y James Bowie, junto con el coronel Travis, eran líderes de los rebeldes atrincherados en El Alamo.

59 Publicado en San Antonio Express, 22 de noviembre de 1902, reproducido en Matovina, Alamo, 1998, pp. 66-72. 
Yo era un muchacho de doce años de edad; por entonces era bastante pequeño y delicado y podría haber pasado por un niño de ocho [edad correcta mencionada en los relatos anteriores]. Mi padre era amigo y camarada de William Smith. Smith había esperado enviar a mi padre y nuestra familia, junto con su propia familia, en una carreta, a Nacogdoches. Estábamos esperando que la carreta fuese traída al pueblo. Mi padre y Smith habían escuchado del acercamiento de Santa Anna, pero no esperaban que él y sus fuerzas arribaran tan temprano como lo hizo. Santa Anna y sus hombres llegaron aquí antes que la carreta que estábamos esperando pudiese hacerlo.

Smith le dijo a mi padre que todos los que eran amigos de los americanos mejor se uniesen a los americanos que habían tomado refugio en El Álamo. Smith y su familia fueron allí, y mi padre y su familia fueron con ellos [...]

Yo vi a Santa Anna cuando arribó. Lo vi desmontar [...] Yo estaba jugando con algunos otros niños en la plaza y cuando Santa Anna y sus soldados vinieron, corrimos y lo contamos a nuestros padres, que casi inmediatamente nos llevaron a El Álamo, a mí y a los otros niños de la familia. Estoy seguro de esto porque vi a Santa Anna varias veces más adelante y después de que salí de El Álamo [...]

Luego afirma que cuando llegaron a El Álamo todas las puertas ya estaban cerradas, y que debieron ingresar por una ventana de la iglesia, que se abrió ex profeso para ellos. Curiosamente, mientras el relato de 1902 mencionaba que nunca había visto a James Bowie, en este de 1907 recuerda lo contrario: "Un día cuando fui adonde Bowie yacía en su catre lo escuché llamar a los que estaban alrede- dor de él y decir...", que los que quisieran podían abandonar el fuerte. Luego de enumerar varias personas que así lo hicieron, agrega:

Bowie le preguntó a mi padre si él deseaba irse [...] Mi padre replicó: "No. Me quedaré y moriré peleando.” Mi madre entonces dijo: "Me quedaré a tu lado y moriré también, con nuestros niños. Nos matarán pronto. El dolor no nos durará mucho.” Así que nos quedamos. Y así murió mi padre, como dije, peleando. Él derribó a uno de sus oponentes al tiempo de caer en el montón de muertos.

\section{Sobre el asalto final, rememora:}

A mi lado había un muchacho americano [...] Ellos lo mataron donde estaba parado y su cuerpo cayó sobre mí. El cuerpo de mi padre yacía cerca del cañón que había estado sirviendo. Mi madre con mi hermanita bebé estaba arrodillada a su lado. Mis hermanos y yo estábamos cerca de ella [...]

Lo último que vi del cadáver de mi padre fue cuando uno de ellos [los soldados mexicanos] sostuvo su linterna sobre él y sobre los muertos que yacían alrededor del cañón que él había servido.

Este relato hace decir a Enrique haber visto caer no sólo a su padre (al parecer en el techo de la iglesia de El Álamo), sino también a David Crockett (en el patio del fuerte) y a James Bowie (en un cuarto donde este había quedado postrado por enfermedad); resulta difícil que un niño -o cualquier otra persona- pudiera haber atestiguado simultáneamente todos estos hechos, que ocurrieron al mismo tiempo en diversos lugares. Sobre la entrevista de su madre con Santa Anna, dice: 
[Santa Anna] preguntó: “¿Donde está su esposo?"

Ella respondió sollozando: "Está muerto en El Álamo."

Santa Anna le preguntó luego dónde estaban los otros miembros de la familia. Ella replicó que estaba informada de que un hermano de mi padre estaba en su ejército (de Santa Anna). Esto era verdad. Mi padre tenía un hermano cuyo nombre era Francisco Esparza, que se unió a las fuerzas de Santa Anna. Fue este hermano quien apareció después ante Santa Anna y pidió permiso para buscar entre los muertos el cadáver de mi padre. El permiso fue concedido. Mi tío encontró el cuerpo de mi padre y lo hizo enterrar en el campo santo [...] Yo no tuve oportunidad de verlo antes de que fuese enterrado, ya que el entierro, como los demás incidentes de esa batalla, fue muy apresurado. Es probable que mi padre fuese el único de los que luchó en el lado de los constitucionalistas y contra las fuerzas del dictador cuyo cuerpo fue enterrado sin haber sido primero quemado. ${ }^{60}$

\section{Entrevistas de 1911}

El mismo Barnes publicó en 1911 una nota centrada sobre cuál fue el sitio exacto en el que se ubicaron las piras funerarias de los defensores de El Álamo. Menciona que un hermano de Enrique Esparza habría muerto en El Álamo, y que Gregorio Esparza habría sido quemado con los demás defensores del fuerte. Barnes escribe:

${ }^{60}$ Charles Merrit Barnes, "El único sobreviviente de El Álamo: Enrique Esparza, quien dice haber estado allí durante el sitio, cuenta la historia de su caída", en San Antonio Express, 12 y 19 de mayo de 1907, reproducido en Matovina, Alamo, 1998, pp. 77-89.
Enrique Esparza [...] sostiene que era un niño de ocho años cuando el sitio y caída de El Álamo tuvieron lugar, y que él estaba en El Álamo con sus padres y uno de sus hermanos. Él dice que su padre y el hermano mencionado fueron muertos en El Álamo y que su madre y él fueron llevados ante Santa Anna después de que el fuerte cayó [...]

Después de esto [la entrevista con Santa Anna] fuimos a buscar el cuerpo de mi padre y mi hermano, pero cuando llegamos otra vez a El Álamo todos los cuerpos habían sido removidos y llevados a la alameda. Los pusieron en dos pilas, una en cada lado de la alameda, y los quemaron. Todos los muertos que murieron durante el sitio y que habían sido defensores de El Álamo fueron quemados, tanto mexicanos como americanos, y mi padre y mi hermano estaban entre ellos, pero no pudimos encontrarlos en ninguna de las pilas, porque los soldados no nos dejaron aproximarnos lo suficiente para examinarlos o reclamarlos.

Les prendieron fuego y los quemaron. Mi madre colocó su mantilla sobre su cara y salió corriendo a gritos de la escena, arrastrándome de la mano con ella. Después de que los cuerpos fueron quemados volvimos varias veces a los dos lugares, hasta que todos los fragmentos fueron removidos y las cenizas fueron dispersadas en todas las direcciones. ${ }^{61}$

Ese mismo año Barnes publicó otra nota, en donde dice que Enrique Esparza tenía menos de diez años de edad al momento de la toma de El Álamo, y que "no hay duda que su padre y uno de sus

${ }^{61}$ Charles Merrit Barnes, "Palas de constructores descubren suelo quemado por las piras funerarias de El Alamo", en San Antonio Express, 26 de marzo de 1911, reproducido en ibid., pp. 101-106. 
hermanos murieron allí, ya que sus nombres aparecen en la lista de los muertos". ${ }^{6}$ Pero en realidad sólo un Esparza aparece en tal lista. Esto, junto con la afirmación de que el cuerpo de Gregorio Esparza habría sido quemado, sugiere que Barnes corrigió y aumentó el relato de Enrique Esparza.

\section{El relato atribuido de 1936}

Aunque Enrique Esparza falleció en 1917, se le atribuye otro relato publicado en 1936 en el libro de Howard R. Driggs y Sarah S. King, titulado Rise of the Lone Star. Está formulado como si Enrique Esparza, al que aquí se llama Gregorio, lo hubiera narrado ante los alumnos de una escuela. ${ }^{63}$ Otra posibilidad es que los autores hayan reconstruido el relato de Enrique a partir de los previamente publicados, o de conversaciones personales con Enrique Esparza o sus descendientes. En este la historia se repite nuevamente en lo esencial, con los siguientes detalles que conviene extractar:

Mi padre prefería seguir a Bowie [antes que a Travis], porque eran amigos. Yo vi al señor Bowie mientras estuvo enfermo [...] Yo me había mantenido cercano al señor Bowie [...]

Cuando se escucharon las trompetas de Santa Anna, ya nos habíamos apresurado

${ }^{62}$ Charles Merrit Barnes, "Hombres todavía vivos que vieron la caída de El Álamo”, en San Antonio Express, 27 de agosto de 1911, reproducido en ibid., pp. 106-107.

${ }^{63}$ La Escuela Bowie, de San Antonio, lo cual resulta probable ya que las familias King y Esparza se conocían y la señora King fue directora de dicha escuela. hacia El Álamo. Cuando mi padre le dijo [a mi madre] que sería mejor que ella se fuese a un lugar más seguro, ella dijo: "¡No, si tú debes morir, yo quiero estar cerca de ti!" Reunimos las pocas cosas que teníamos: un metate, dos sillas, cuatro pieles y algunos utensilios de cocina. En un paquete estaba mi hermana bebé. Mis hermanos pequeños y yo cargamos lo que pudimos. Yo era el mayor, tenía nueve años [...]

Una noche mi padre capturó a un mexicano que estaba rondando alrededor, y lo hizo prisionero. Era uno de los soldados de Santa Anna. Durante el sitio diría a los texanos lo que significaban los toques de corneta del enemigo. Escuché que después este pobre hombre fue muerto, porque Santa Anna pensó que era un desertor [...]

Era temprano en la mañana. De un profundo sueño, corrí al patio. Quedé fijado al piso. Los texanos mataron a muchos hombres de Santa Anna, pero más y más seguían viniendo por las escaleras. Mi padre fue muerto $[\ldots]$

Respecto de la entrevista con Santa Anna, recuerda que este preguntó a su madre por qué luchaba contra sus compatriotas, y que esta respondió:

"No son mis compatriotas; nosotros somos texanos." A lo que Santa Anna replicó que debería cortarle las orejas, para luego ordenar se le diese una cobija y dos dólares [...]

Nos quedamos en San Antonio con mi tío. Él no había tomado parte en la guerra. Era demasiado viejo. Mi tío encontró el cuerpo de mi padre entre los muertos, y lo enterró.

"¿Los vio usted quemar los cuerpos de estos texanos, señor Esparza?”, preguntó alguno [de los alumnos]. 
No, pero escuché que ellos sí quemaron los cuerpos. ${ }^{64}$

Relatos de otros descendientes

de Gregorio y Francisco Esparza

Los descendientes de Gregorio y Francisco Esparza han cultivado la historia oral de sus familias. Como en toda tradición familiar, máxime si esta se remonta a épocas lejanas, las fuentes son difíciles de precisar, y las narraciones tienden a ser ambiguas, cuando no contradictorias. Por ejemplo, George Benavides, descendiente de Gregorio Esparza, sostiene que fue su viuda Ana Salazar quien, al entrevistarse con Santa Anna después de la caída de El Álamo, pidió permiso para buscar y enterrar el cuerpo de su difunto esposo, alegando para obtenerlo que su cuñado Francisco era miembro del ejército de Santa Anna. ${ }^{65}$ En contraste, Richard D. Esparza, descendiente de Francisco Esparza, afirma que este último, como miembro de la Compañía Leal del Presidio, fue convocado a servicio en la tarde del día en que cayó El Álamo, con la encomienda de ayudar a enterrar a los mexicanos caídos en la batalla; Francisco y sus hermanos Antonio y Víctor habrían aprovechado la oportunidad para buscar el cuerpo de Gregorio, al que encontraron dentro de la capilla de El Álamo; al aparecer Cos en el lugar, Francisco habría pedido y obtenido permiso para enterrar a Gregorio "con los ritos de la Iglesia"; luego, trasladaron el cuerpo en una carreta, a la plaza de las Islas y la iglesia de San Fernando, donde

\footnotetext{
${ }^{64}$ Reproducido en Groneman, Eyewitness, 1996, pp. 180-187.

${ }^{65}$ Jackson, Alamo, 1997, pp. 95-97.
}

clamaron por el padre De la Garza, quien realizaría "los últimos rituales de acuerdo con la Iglesia católica" y enterraría a Gregorio en el campo santo. ${ }^{66}$

\section{FUENTES CONSULTADAS}

\section{Archivos}

Catholic Archives at San Antonio (Archivos Católicos de San Antonio), Chancery of the Archdiocese of San Antonio (Cancillería de la arquidiócesis de San Antonio), San Antonio.

BCC Bexar County Courthouse Archives (Archivos de la Corte del Condado de Bexar), San Antonio.

DRTL Daughters of the Republic of Texas Library (Biblioteca de las Hijas de la República de Texas), El Álamo, San Antonio.

GLO Texas General Land Office (Oficina General de Tierras de Texas), Archives and Records Division (División de Archivos y Registros), Austin.

\section{Bibliografía}

-Asbury, Samuel E., "The Private Journal of Juan Nepomuceno Almonte, February 1-April 16, 1836", Southwestern Historical Quarterly, julio de 1944.

-Becerra, Francisco, A Mexican Sergeant's Recollections of the Alamo and San Jacinto, Jenkins Publishing Co., Austin, 1980.

-Daughters of the Republic of Texas, The Alamo Long Barrack Museum, Dallas, 1985. Austin, Texas, 1986. , Muster Rolls of the Texas Revolution,

${ }^{66}$ Ibid., pp. 99-104. 
-Handbook of Texas, The New, The Texas State Historical Association, Austin, 1996.

-Filisola, Vicente, Materiales para la bistoria de la guerra de Tejas, Editora Nacional, México, 1968 (facsímil de la 1a. ed. por Tipografía de R. Rafael, México, 1849).

-Groneman, Bill, Alamo Defenders. A genealogy: the People and their Words, Eakin Press, Austin, 1990.

, Eyewitness to The Alamo, Republic of Texas Press, Plano (Texas), 1996.

-Jackson, Ron, Alamo Legacy. Alamo Descendants Remember the Alamo, Eakin Press, Austin, 1997.

-Henson, Margaret Swett, Lorenzo de Zavala. The Pragmatic Idealist, Texas Christian University Press, Forth Worth, 1996.

-Laos, Walter N., Esparza, ed. del autor, s. l., 1999.

-Matovina, Timothy M., The Alamo Remembered. Tejano Accounts and Perspectives, University of Texas Press, Austin, 1998 (1a. ed., 1995).

-Matthews, Cahndice, Gregorio Esparza. Alamo Hero, Eakin Press, Austin, 1996.

-Miller, Thomas Lloyd, "Mexican-Texans at The Alamo", The Journal of Mexican American History, vol. II, núm. 1, otoño de 1971.

, Bounty and Donation Land Grants of Texas,1835-1888, University of Texas Press, Austin, 1967.

-Myers Myers, John, The Alamo, University of Nebraska Press y Bison Books, Lincoln (Nebraska) y Londres, 1973 (1a. ed., 1948).

-Montejano, David, Anglos y mexicanos en la formación de Texas, 1836-1986, CONACULTA/ Alianza, México, 1991.
-Pena, José Enrique de la, With Santa Anna in Texas. A Personal Narrative of the Revolution, Texas A \& M University Press, College Station, Texas, 1997.

-Ragsdale, Crystall Sasse, Women E Children of The Alamo, State House Press, Austin, 1994.

-Rendon Lozano, Rubén (ed. por Mary Ann Noonan Guerra), Viva Texas. The Story of the Tejanos, the Mexican-born Patriots of the Texas Revolution, The Alamo Press, San Antonio, Texas, 1985.

-Santa Anna, Antonio López de, "Informe dirigido al secretario de Guerra y Marina, general José María Tornel”, en John J. Jenkins (ed.), The Papers of the Texas Revolution, Presidial Press, Austin, 1973.

-Seguín, Juan N. (ed. Jesús F. de la Teja), $A$ Revolution Remembered. The Memoirs and Selected Correspondence of Juan N. Seguin, State House Press, Austin, 1991.

-Tinkle, Lon, 13 Days to Glory. The Siege of The Alamo, McGraw-Hill, Nueva York, 1958.

-Williams, Amelia, "A Critical Study of the Siege of The Alamo and of the Personnel of Its Defenders", en The Southwestern Historical Quarterly, The Texas State Historical Association: parte I, vol. XXXVI, núm. 4, abril de 1933, pp. 251-287; parte II, vol. XXXVII, núm. 1, julio de 1933, pp. 1-44; parte III, vol. XXXVII, núm. 2, octubre de 1933, pp. 79-115; parte IV, vol. XxXVII, núm. 3, enero de 1934, pp. 157-184, y parte v, en vol. xxxviı, núm. 4, abril de 1934, pp. 237-312. 
SECUENCIA

Revista de historia y ciencias sociales 